\title{
Pressure Pulse Contour-derived Stroke Volume and Cardiac Output in the Morbidly Obese Patient
}

\author{
Donald P. Bernstein
}

Published online: 4 June 2008

(C) Springer Science + Business Media, LLC 2008

Erratum to: OBES SURG

DOI 10.1007/s11695-007-9378-6

Subsequent to e-publication of the above Review Article (which is the preceding article), the author noted that he had made an error in the description of Eq. 8. The sentence above Eq. 8 currently reads, $K$ is the ratio of uncalibrated pressure pulse contour-derived $\mathrm{SV}\left(\mathrm{SV}_{\mathrm{UNCAL}}\right)$ and transpulmonary TDCO-derived $\mathrm{SV}$ (i.e. $K=\mathrm{SV}_{\mathrm{UNCAL}} / \mathrm{SV} \mathrm{TD}$ ). Thus,
$\mathrm{SV}_{\mathrm{CAL}}=\mathrm{SV}_{\mathrm{UNCAL}} \times\left(\frac{\mathrm{SV}_{\mathrm{UNCAL}}}{\mathrm{SV}_{\mathrm{TD}}}\right)$

The sentence and corresponding equation should read, $K$ is the ratio of transpulmonary TDCO-derived SV and uncalibrated pressure pulse-derived $\mathrm{SV}$ (i.e. $K=\mathrm{SV}_{\mathrm{TD}} /$ $\left.\mathrm{SV}_{\mathrm{UNCAL}}\right)$. Thus,

$\mathrm{SV}_{\mathrm{CAL}}=\mathrm{SV}_{\mathrm{UNCAL}} \times\left(\frac{\mathrm{SV}_{\mathrm{TD}}}{\mathrm{SV}_{\mathrm{UNCAL}}}\right)$.
The online version of the original article can be found at http://dx.doi.org/10.1007/s11695-007-9378-6.

D. P. Bernstein $(\triangle)$

Department of Anesthesia, Palomar Medical Center

and Palomar-Pomerado Research Institute,

Escondido, CA 92025, USA

e-mail: strokevolumedon@aol.com 